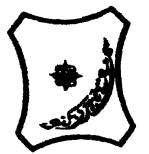

Bayero Journal of Pure and Applied Sciences, 11(2): 39 - 50

Received: November, 2018

Accepted: December, 2018

ISSN $2006-6996$

\title{
UNDERSTANDING INSECT PARASITOIDS LIFE HISTORY BEHAVIOUR FOR OPTIMAL UTILIZATION IN BIOLOGICAL CONTROL OF TROPICAL INJURIOUS PEST - A REVIEW
}

\author{
Audi, A. H. ${ }^{* 1}$ and Biliyaminu, $A^{2}$. \\ ${ }^{1}$ Department of Biological Sciences, Faculty of Life Sciences, Bayero University, P.M.B. 3011 Kano, \\ Nigeria \\ *Corresponding author: audigenesis@yahoo.com
}

\begin{abstract}
Parasitoids are a key component of most terrestrial ecosystems due to their numbers and ecological significance due to the nature of their life cycle which partly depend on other insects for their survival. They are vitally important for the maintenance of biodiversity being involved in a vast number of trophic interactions including regulatory effect on insect pest populations. There are four insect orders that are particularly prominent for this type of life history. These are Hymenoptera, Diptera, Coleoptera and Neuroptera. The greatest number is found in the order Hymenoptera, which account for nearly $75 \%$ of the estimated number of parasitoid species. There are considerable variations in parasitism of insect parasitoids. These may be $I$ diobionts, whose hosts stop development, when they are parasitized and Koinobionts which allow the hosts to continue their development until the parasitoid's offspring matures. Reports have shown that species richness of koinobionts parasitoids tends to decrease toward the tropics while idiobionts richness does it less severely. Such pattern was however intrinsically related to the host feeding niche. In hymenopteran parasitoid complexes however the richness of both idiobionts and koinobionts falls toward the tropics in exophytic hosts, while on endophytic hosts, there are no changes in species richness for both types of parasitoids. Biological control is the central stone of integrated pest management (IPM) paradigm and natural enemies are becoming an increasingly desirable prospect in lieu of chemical insecticides. Although hymenopteran parasitoids are widely used in the control of insect pest due to their Diversity and species richness, Coleopterans parasitoids could be useful in suppressing pest due to the pattern of their parasitism. Host selection strategies of insect parasitoids are largely influenced by chemical signals from plants attacked by insect pest. Their competitive fitness and reproductive success will therefore depend extensively on the ability to employ such signals more efficiently.

Keywords: Behaviour, Biological control, Diversity, Insect parasitoids, Plant metabolites.
\end{abstract}

INTRODUCTION

The term "parasitoids" describe insects that spend a significant portion of their life mostly in a parasitic relationship in attached or within a single host (Gullan and Cranston, 2004). Insect parasitoids are usually defined as a species whose larvae develop by feeding in or on the body of an arthropod host, eventually killing it (Eggleton and Belshaw, 1992; Godfray, 1994; Quicke, 1997). Adult parasitoids are usually free living and highly mobile, being proficient at searching for hosts, only larval stages kill the host (Quicke, 1997; Hoedjes et al., 2011). Parasitoids can be classified either as endoparasitoids if the larvae feed inside the hosts, or ectoparasitoids that live externally, normally with their mouth parts buried in their host's body. Parasitoids can also be divided into two different groups, depending on the host growth: Koinobionts, which usually allow the host to continue its development after ovipositions; and Idiobionts, which do not (Askew and Shaw, 1986). Idiobionts either develop entirely within a host's egg or pupal stage, or if attacking mobile larval stages as ectoparasitoids, they inject venom either causing permanent paralysis as arrested development, modify the host's immune system or its metabolic functions (Godfray 1994; Quicke, 1997). Most Koinobionts, on the other hand, do not paralyze the host, or do it just temporarily, and the host can continue to grow while the parasitoid larvae feed on its hemolymph or non - vital tissues (Shaw, 1997). Normally, koinbiont species attack young hosts, whereas idiobionts that attack larval hosts generally attack more mature ones (Godfray, 1994; Quicke, 1997). 
Many idiobionts are ectoparasitoids, feeding mostly on concealed hosts. In contrast, koinobionts are mainly endoparasitoids attacking mobile or fairly free - ranging host (Quicke, 1997; Mayhew and Blackburn, 1999). This dichotomy between idiobionts and koinobionts also reflected in the parasitoids range: Koinobionts usually have a narrower host range than idiobionts, being therefore typically considered specialist (Sheehan and Hawkins, 1991; Hawkins, 1994; Shaw 1994). One reason for this may be that koinobionts have a more prolonged interaction with the immune system of their host, and adaptations to overcome this difficulty probably restricted the number of hosts that they can use successfully.

Some parasitoids are parasitoids of other parasitoids which are termed hyperparasitoids which are often referred to as secondary parasitoids or tertiary parasitoids: parasitoids of parasitoids of parasitoids (Hawkins, 1994). In solitary species (Aleochara biliniate ( Coleoptera: Staphylinidae), only a single parasitoids is able to develop with a host, while in gregarious species, several individual (ranging from two to thousands, depending upon species) are able to develop into a single host (Gaston, 2000). Parasitoids comprise of $10 \%$ of all insects. There are four insect orders that are particularly prominent for this type of life history (Eggleton and Belshaw, 1992). These are hymenoptera (Ants, Bees, Sawflies and Wasps), Diptera (True flies), Coleoptera (Beetles) and Neuroptera (Lacewings). Among these four insect orders, most of the parasitoids belong to Hymenoptera and Diptera (Eggleton and Belshaw, 1992; Godfray, 1997) but the greatest number is found in the order hymenoptera, which account the nearly $75 \%$ of the estimated number of parasitoid species (Belshaw et al., 1994; Feener and Brown, 1997;). While some parasitoids are sexual, producing males and females, others reproduce asexually through parthenogenesis. Within the hymenoptera, sex determination is haplodiploid with diploid females developing from fertilized eggs, and haploid males developing from unfertilized eggs (Godfray, 1994).

Parasitoids are a key component of must terrestrial ecosystems due to their numbers and ecological importance (Lasalle and Gauld, 1993). They are vitally important for the maintenance of the diversity of other animals and plant species, being involved in a vast number of tropic interactions (Hawkins and Lawton, 1987; Muller et al., 1999, Lewis et al., 2002) and having a regulatory effect on arthropod populations (Hassell, 2000; Letourneau et al.,
2009). In spite of their ecological importance, relatively little is known about the diversity, distribution and biology of parasitoids. The review will therefore provide base line information toward understanding parasitoids ecology for successful utilization in biological control programme of sub-Saharan Africa.

\section{Diversity and trophic interactions of Insect Parasitoids}

Although the hymenoptera are one of the most species - rich and abundant groups of organisms, with estimates of total species richness ranging from 130,000 to 2.5 million (Gauld and Bolton, 1988; Lasalle and Gauld, 1991; Ulrich, 1999), the number of described species is only approximately 115,000 (Lasalle and Gauld, 1993), indicating that most species are still undescribed. Several works have examined the geographic gradients of parasitoid diversity, particularly of Ichneumonidae. Various studies based on data from field survey initially suggested that this family is less species - rich towards the tropics than on temperate regions (Askew and Shaw, 1986; Noyes, 1989, Askew, 1990; Hawkins, 1994, Skillen et al., 2000). Quicke and Kruft (1995) found the same pattern for Braconidae of North America. In contrast to the Broconidae and Ichneumonidae, there is little evidence for the existence of such a pattern in various chalcidoidea families (Haspenheide, 1979; Noyes, 1989; Askew, 1990). In an attempt to understand the apparent anomalous diversity of the ichneumonidae, some authors found that the observed latitudinal trends of species richness vary with the dichotomy between idiobiosis and koinobiosis (Askew and Shaw, 1986; Hawkins et al., 1992). In fact it was shown that koinobionts richness decreases toward the tropics, while idiobionts richness does not, or does it less severely (Askew and Shaw, 1986; Askew, 1990). However, it has also been advocated that such pattern is intrinsically related to the host feeding niche (Hawkins et al., 1992; Hawkins, 1994). Exophytic host (i.e. those that are not protected by any plant tissue) support more parasitoids in the temperate zone than in the tropics (Skillen et al., 2000), whereas endophytic hosts (i.e. those that live in concealed situations, such as wood borers gallers and leaf miners) generally support at least as many parasitoids in the tropics as they do in temperate regions, with some types of host even supporting more. Report by Hawkins (1994) observed that the richness of both idiobionts and koinobionts falls toward the tropics in exophytic hosts, while on endophytic hosts, there are no change in species richness for both types of parasitoids. 
BAJOPAS Volume 11 Number 2, December, 2018

Considering global data at ichneumonoidea and diptera distribution, this same author found that on endophytic hosts, there are also same reductions in idiobionts and koinobionts species richness of ichneumonoids with decreasing latitude, although a smaller than the declines found in exophytics hosts, and that the overall dipteran species richness slightly declines toward the tropics (although richness is maintained on endophytic hosts). Chalcidoids, on the other hand, did not show an evident pattern regarding host feeding niche, but they tended to be as rich in tropical as in temperate regions and in some cases even richer (Hawkins, 1994).

\section{Hymenopteran Parasitoids}

Hymenopteran parasitoids constitute nearly $78 \%$ of the estimated number of reported parasitoid species and due to this great abundance; they have served as models of selection for nearly all modern research on insect parasitoids (Hawkins and Sheehan, 1994). There are many parasitoid species belonging to different families in this order, however, these four families namely Braconidae, Ichneumonidae, Chalcididae, Trichogrammatidae are very important in insect pest management (Wharton, 1993).

This family Braconidae is considered as one of the most important and largest in the order hymenoptera, consisting of more than 15, 000 valid species (Quicke and Van Achterberg, 1990). Family Braconidae along with the Ichneumonidae forms a distinctive super-family among the assemblage of hymenopteran called the parasitic wasps (Gauld and Balton, 1988). The adult braconids mostly oviposit in, on, or near other insects, with the immature stages completing their development at the host's expense. They are highly host specific, being so specific that as larvae only feed on a narrow host range. They are important in controlling many crop yield insect pests like Lepidoptera and Diptera. Braconids have been particularly heavily involved in the so called classical biological control of insect pests and more recently in integrated pest management programmes, often with considerable success (Shaw and Huddleston, 2012). Studies have reported a significant importance of an obligate larval endoparasitoid, Cotesia chilonis (Hymenoptera: Braconidae) that effectively regulates the density of Chilo suppressalis (Lepidoptera: Crambidae), one of the economically most important rice pests in China and other Asian countries (Lou et al., 2014; Qi et al., 2014). This braconid has also been imported into several African countries as a means to control lepidopteran stem borers (Hailemichael et al., 2008).

The family chalcididae consists of over 1500 species and 90 genera worldwide (Noyes, 2011). Chalcidids are mainly solitary, endoparasitoids of Diptera and Lepidoptera, though a few species attack Neuroptera, Coleoptera and Hymenoptera. Most of them are idiobionts, depositing eggs into more or less fully grown hosts. Those host stages may be as mature larvae (in the case of parasitoids of Diptera) or young pupae (in the case of Lepidoptera) (Boucek and Narendran, 1981). Reports have shown that Species of the genus Smicromorpha are specialized larval parasitoids of the green ant, Oecophylla smaragdina (Narendran, 1979; Naumann, 1986 and Darling, 2009) S. masneri, were also found emerging from 0 . smaragdina nests collected in Vietnam which strongly suggests that these wasps are also primary parasitoids of weaver ants (Darling, 2009). Moreover, two other species, $S$. keralensis (Narendran, 1979) and $S$. minera (Naumann, 1986) have been observed hovering over nests of $O$. smaragdina in India and Australia, respectively,

Family ichneumonidae is one of the most important parasitoid families which are further divided into 37 sub-families with an estimated 60000 species in the world (Yu et al., 1992). Ichneumonids utilize a diverse group of insects as their hosts and play an essential role in the biological control of insects. The common host includes larvae and pupae of Lepidoptera, Coleoptera and Hymenoptera (Gupta, 1991). Reports have shown that Gregopimpla kuwanae Viereck (Hymenoptera: Ichneumonidae) has frequently been found as a gregarious ectoparasitoid of Rice Skipper Parnara guttata (Matsumura, 1992; Momoi, and Nisida, 1994) though it is also known as an important natural enemy of the silver $\mathrm{Y}$ moth Autographa gamma (L.) Studies on Oviposition and Development of Gregopimpla kuwanae Viereck on $P$. guttata shows that, Survival of parasitoid offspring decreased with the increasing number of eggs on each host. Females used $18.9 \%$ of hosts for host feeding, killing the hosts with no exception. Oviposition did not occur on hosts used for feeding purpose, indicating that the parasitoid was a nonconcurrent, destructive host feeder. Females started oogenesis only after they had destructively fed on hosts (Takatoshi, 2016). 
BAJOPAS Volume 11 Number 2, December, 2018

The family Trichogrammatidae consists of some tiny wasps with majority of insect species having adult size less than $1 \mathrm{~mm}$ in length. This family consists of 80 genera with approximately 840 species. Trichogrammatids parasitize the eggs of many different insects order especially insect order Lepidoptera and play an important role as bio-control agent. The female after mating lay eggs inside the host eggs, the eggs when hatched feed on host eggs and then adult emerge. The life cycle is completed in $8-12$ days depending upon environmental conditions (Saljoqi et al., 2015). Reports have shown that, most Trichogramma species, such as T. platneri Nagar-katti, T. pretiosum Riley, and T. brassicae Bezdenko host feed during oviposition (Blanché et al., 1996; Mills and Kuhlmann, 2004), However study on Ovipositional behaviour of trichogramma fuentesi an egg Parasitoid of Cactoblastis cactorum showed that T. fuentesi females did not host feed following oviposition. Trichogramma fuentesi displayed six types of behavior: walking, resting, grooming, drumming, drilling, and egg laying (Mills and Kuhlmann, 2004). Host feeding has been considered a fitness trade-off for parasitoids (Rivero and West, 2005). Parasitoids that host feed can increase their longevity and future production of eggs, or they can forgo host feeding and slowly starve, decreasing their longevity but increasing their immediate ovipositional output of their current eggs (Lewis et al., 1998; Rivero and West, 2005)

\section{Dipterous Parasitoids}

The insect order diptera includes several families with an estimated 16, 000 species of parasitoids, or approximately $20 \%$ of the total number of species with this life - style. Among these parasitoids families Tachinidae is the largest and most important family consisting of about 10, 000 parasitoids of the major agricultural pests (Eggleton and Belshaw, 1992). All tachinid flies are larval parasitoids of insects. Most tachinid flies are larger than a house fly, but they range in size, from 2- 20mm. Studies on Evolution, Behavior, and Ecology of tachinid shows that all tachinid species are mostly endoparasites and majority are ovoviviparous, depositing eggs that contain fully developed first instars. The primary host includes lepidopteran pests, but some species attack coleopteran insects (Evenhuis and O'Hara, 2008). Report have shown that early larval stages of tachinids embed themselves in specific tissues rather than float free in the hemocoel (Belshaw, 1994) and at least one highly polyphagous species, Compsilura concinnata, undergoes most of its larval development in the gut (i.e., between the peritrophic membrane and gut wall) (Ichiki and Shima, 2003).

\section{Coleopteran Parasitoids}

Coleopteran parasitoids are characterized by their mobile early larvae, which search for suitable host on their own (Eggleton and Belshaw, 1993). Because the length of time the larvae can spend searching is constrained by the resources available from the egg, the probability of timely host location increases with the proximity to host oviposition site (Eggleton and Belshaw, 1993; Godfray, 1994). The Following families of beetles contain parasitoids:

Carabidae is one of the largest family of beetles, with about 30,000 known species. Most are predators and many are important in natural and biological control. About 500 species of ground beetles are parasitoids, primarily of soildwelling insects. These are ectoparasites, feeding attached to the outside of their single host. Many of these are in the genus Lebia, which includes parasites of members of the leaf beetle family (Chrysomelidae). Lebia grandis parasitizes Colorado potato beetle pupae (Georgen, 2009).

The Staphylinidae (Rove Beetles) is another large family, with about 30,000 species worldwide. Many are predators and some of these are important in biological control; about 500 species are known to be parasitoids. Most of the parasitoids attack the pupae of flies, such as filth-breeding flies (house flies, blow flies, flesh flies, etc.). One species, Aleochara bilineata, is an important parasite of cabbage maggot (Hassell, 2000). The beetles are 5-7 mm long and black, and $A$. bipustulata often bears two reddish spots on the elytra (Andreassen et al., 2007). Larvae of $A$. bipustulata and $A$. bilineata are parasitoids on $D$. radicum puparia (Fuldner, 1960). The parasitisation rate of $D$. radicum puparia in production fields varies from a few per cent up to $>80 \%$ (Meyling et al., 2013). The adult females are attracted to host patches by volatile cues released from plants damaged by $D$. radicum larvae, whereupon they oviposit in the soil close to the plant (Fournet et al., 2001). The larva feeds on the host and subsequently pupates inside the host puparium (Andreassen et al., 2007). The species differ in host range and preference. Aleochara bilineata has a narrow host range, comprising primarily $D$. radicum, $D$. floralis, $D$. antiqua and $D$. platura. Besides the phytophagous Delia spp., Psila rosae and Pegomya spp., A. bipustulata 
BAJOPAS Volume 11 Number 2, December, 2018 may also parasitise certain dung and carrion feeding Diptera (Andreassen et al., 2009). However, $A$. bipustulata generally prefers smaller puparia than $A$. bilineata (Jonasson, 1994).

Rhipiceridae (cedar beetles) also comprise a very small family, with only about a half dozen species known in the United States. Members of the genus Sandalus parasitize the nymphs of cicadas in the soil, but are not very abundant (Marino and Landis, 1996). In Virginia Rhipiceridae is represented by two species, Sandalus niger Knoch and $S$. petrophya Knoch, the latter of which is documented from the state for the first time. Elzinga (1977) reported that the larvae of Sandalus niger develop as ectoparasitoids of immature cicadas after discovering a pupa and cast larval exoskeleton of the beetle within a dead and hollowed-out cicada nymph. This assertion was later supported by descriptions of the first instar triungulin of $S$. niger by Arthur and Brent (2012) that is typical of other beetle parasitoids.

In the Meloidae, the larvae of some blister beetles attack ground-nesting bees; others attack the egg cases of grasshoppers. Because egg cases contain many eggs, some people consider this group of blister beetles to be predators. But because each larva consumes only a single egg case, others consider these to be egg-case parasitoids (Gaston and Hudson, 1994; Goegen, 2009). Report has shown that some meloid females can lay their eggs on flowers where the triungulins easily access a bee to be transported to the host nest (Vereecken and Mahe, 2007)) Others lay the eggs in the ground, and the triungulins have to locate a suitable site from which to find a host sometimes attracting the bees through pheromone mimicry (Saul-Gershenz and Millar, 2006). However, in Cissites Latreille, Hornia Riley, and Meloetyphlus Waterhouse, the eggs are placed near or inside the host nest (Garofalo et al., 2001)

\section{Effect of Host Plant Chemical Metabolites on Foraging Behaviour of Insect Parasitoids}

The volatile chemicals whether derived from organisms associated with the hosts, the host itself, the host's food, or a blend of these factors are mainly responsible for attracting the parasitoid to a host habitat. Blends of volatile chemicals from the plants are released into the air after insect herbivores attack (Mumm and Dicke, 2010). The plant uses these chemical for several purposes including direct protection against insect herbivores (Unsicker et al., 2009) and attracting of natural enemies of herbivore within plant signaling (Heil, 2008). In a study conducted by Turlings et al. (1991) on the host searching behaviour of larval parasitoids of Lepidopterans, attractions of parasitoids toward odor-cues emitted by damaged plants was observed. Similarly in young corn seedlings, a few hour after the caterpillar damage, several highly odorous terpenoids are released to attract the natural enemies in response to larval damage. This response is systemic, as the same terpenoids are also released from undamaged leaves of injured plants (Turlings et al., 1991). The insect damages to plants resulted in induced plant volatiles which are called herbivore induced plant volatiles (HIPVs) which attract the natural enemies of the pest species and in this way protect the crop (Soler et al., 2007).

In some parasitoids like Cotesia marginiventris, the levels of plant wound releases volatile compound may have allowed the wasps to specifically recognize plants infested by hosts (Erb et al., 2010). The adverse effects of food plant characteristics on insect performance are usually less pronounced in the parasitoid than in the herbivore (Benrey et al., 1998; Harvey et al., 2003; Sznajder and Harvey, 2003), Secretion and/or detoxification of plant allelochemicals by the host may dilute the effect of these compounds on the development of the parasitoid. The efficiency of the host immune response may be reduced when the host is feeding on more toxic plant genotypes or species (Karimzadeh and Wright, 2008), which in turn may increase parasitism success. The feeding strategy of the parasitoid larva may influence the extent to which parasitoid offspring are exposed to the adverse effects of plantderived compounds. In a research conducted by Gols et al. (2008) found that haemolymphfeeding parasitoid Cotesia glomerata L. developed equally well on hosts feeding on Sinapis arvensis L. and Brassica nigra, whereas its host, Pieris brassicae L., was significantly smaller and took longer to complete development on $S$. arvensis. 


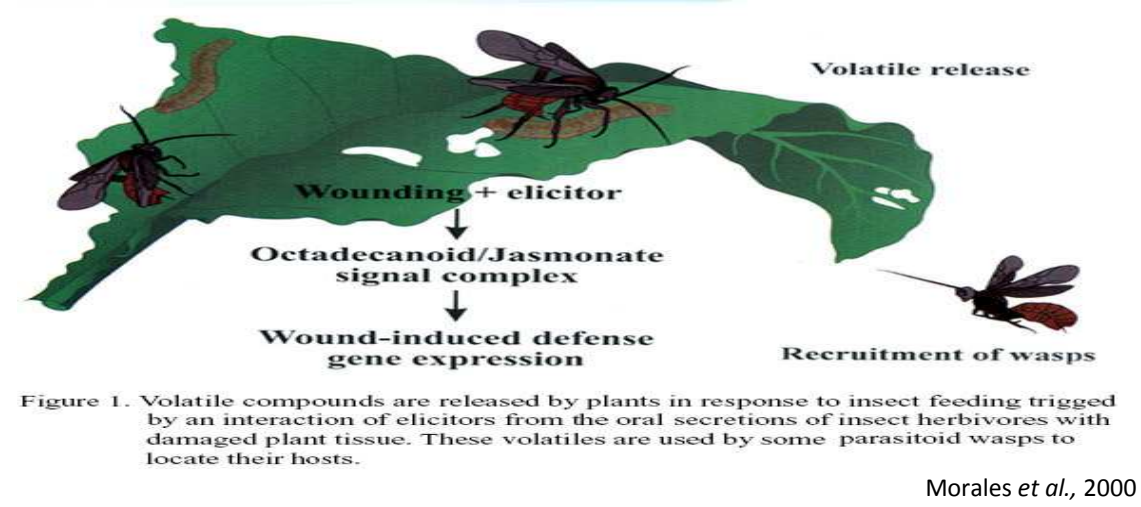

Effect of Host Age Characteristics on Development of Parasitoids

For koinobionts, in which hosts continue feeding and growing long after parasitism, host suitability is largely determined by host age (Campbell and Dufey, 1979), as it affects not only its size and consequently the available food quantity for parasitoid larva, but also its nutritional value (e.g., composition of hemolymph and host tissues) (Jervis and Copland 1996, Harvey et al., 2000, Harvey and Strand, 2002). This variation has been shown to have strong effect on many morphological, biological and ecological traits such as duration and survival of immature stages, adult size and longevity, sex ratio, egg load, fecundity and others, influencing in this way the population dynamics of larval parasitoids of lepidopterous pests (Strand et al., 1988, Reitz, 1996). Reports have shown that, age of the host at parasitism had a significant effect on the duration of development of a parasitoid (Harvey et al., 1994). Parasitoids developing in a very young hosts spend extended periods as first instars ingesting host hemolymph at a reduced rate, until the host reaches 5th instar and food for the parasitoid becomes abundant (Corbet 1968, Hemerik and Harvey,1999). The larvae of many koinobionts avoids growing exponentially in young hosts, because if the host is consumed before it has grown large enough to support the wasps complete development, both will perish (Hemerik and Harvey, 1999). Developmental arrest explains the significantly longer developmental period of $V$. canescens in very young $E$. kuehniella larvae, and also has been observed when the wasp develops in Plodia interpunctella Hubner (Harvey et al., 1994; Harvey and Thompson, 1995). In a study to determine Inter- and intra-specific host discrimination in gregarious and solitary endoparasitoid wasps both $C$. kariyai and $M$. pulchricornis female wasps significantly preferred healthy M. separata over four day-old hosts previously oviposited by a heterospecific or conspecifics. Rejection of parasitized hosts increased especially when the second parasitoids foraged 4-7 days after the initial parasitism previously by both inter-specific and intra-specific females (Harvey et al., 2013b).

Manipulation of host growth during parasitism has been recorded in many koinobiotic larval endoparasitoids of lepidopterous pests. Interactions between the koinobiont Hyposoter exiguae (Viereck) (Hymenoptera: Ichneumonidae) and various host species are characterized by host developmental arrest, which varies with host species and instar attacked in accordance with the nutritional requirements of the parasitoid (Smilowitz and Iwantsch 1973, Beckage and Templeton, 1985; Harvey, 2000).

\section{Competition/Coexistence parasitoids}

among

In nature, a single species of host can have multiple species of natural enemies (Price, 2002; Bogran et al., 2002; Harvey et al., 2009) which often results in intense interactive competition/interference for the host resource (Harvey et al., 2013). Competitive interaction frequently occurs in parasitoids, because parasitoids, unlike most predators, usually have narrow host ranges (Harvey et al., 2013b). Godfray (1994) emphasized that competition in parasitoid communities is a key factor in shaping the structure of natural enemy communities. Understanding the interspecific competition among parasitoid species is crucial to the selection of appropriate biological control agents for introduction and release (Mackauer, 1990). In parasitoids, larvae can compete for space and food (Boivin and Brodeur, 2006), adults can experience local mate competition at emergence, and also, since the distribution of hosts is usually aggregative (Godfray 1994; Wajnberg, 2006), foraging adult females may face direct competition for hosts (Godfray 1994; Harvey et al., 2013a). Intraspecific competition 
BAJOPAS Volume 11 Number 2, December, 2018

then occurs when several individual parasitoids of the same species exploit or attempt to exploit the same resource patch, sometimes at the same time. The simultaneous presence of competitors in a host patch leads to interference competition (Godfray 1994; Goubault et al., 2005).

Studies on the outcome of Intrinsic competition and its effects on parasitoid survival, development, and Fitness shows that success of competition between parasitoids attacking the same host is strongly time dependent; when there are time lags between the first and second oviposition, the first parasitoid to have oviposited generally outcompetes later parasitoids (De Moraes et al., 1999; De Moraes and Mescher, 2005). De Moraes et al. (1999) found that eggs of the solitary endoparasitoid Microplitis croceipes hatched earlier than eggs of another solitary endoparasitoid, Toxoneuron nigriceps, when they were laid into their common host, Heliothis virescens, at the same time. As a result, $M$. croceipes dominated $T$. nigriceps when ovipositing first and even when the latter species had an 8-h head start.

In another study to compare the outcome of competition between the larvae of two solitary secondary hyperparasitoids, generalist Gelis agilis and specialist Lysibia nana, on pupae of their primary parasitoid host, Cotesia glomerata, it was found that both species out competed each other when they had a 24- to 48-h head

\section{REFERENCES}

Andreassen, L. D., Kuhlmann, U., Mason, P. G. and Holliday, N. J. (2007). Classical biological control of the cabbage root fly, Delia radicum, in Canadian canola: an analysis of research needs. CAB Reviews: Perspectives on Agriculture, Veterinary Science, Nutrition and Natural Resources, 86: $1-13$

Andreassen, L.D., Kuhlmann, U., Mason, P.G. and Holliday, N. J. (2009). Host range testing of a prospective classical biological control agent against cabbage maggot, Delia radicum, in Canada. Biological Control, 48 (2): 210-220.

Askew, R. R. (1990). Species Diversity of Hymenopteran taxa in Sulawesi. In: Knight WJ. Holloway JD (eds) Insects and the rain forest of sourth east Asia (Wallacea) 250-260 pp.

Askew, R.R., and Show M.R., (1986). Parasitoid Communities: their Size, Structure and Development. In: Waage J. Greathead D. (eds) Insect Parasitoids. Academic Press London. 225-264 pp start in terms of oviposition. However, when $L$. nana oviposited first, $G$. agilis began to dominate when the time lag exceeded $96 \mathrm{~h}$ between the first and second oviposition. $G$. agilis switched from being a competitor of $L$. nana for control of resources of $C$. glomerata to an exploiter, with female $G$. agilis readily ovipositing on the growing larvae of $L$. nana. By contrast, $L$. nana rejected hosts containing large larvae or pupae of $G$. agilis. The switch is presumably dependent on the $L$. nana larvae reaching a size large enough to be detected and parasitized by G. agilis (Harvey et al., 2011).

\section{CONCLUSION}

Biological control is the central stone of integrated pest management (IPM) paradigm and natural enemies are becoming an increasingly desirable prospect in lieu of chemical insecticides. Although hymenopteran parasitoids are widely used in the control of insect pest due to their Diversity and species richness, Coleopterans parasitoids could be useful in suppressing pest due to the pattern of their parasitism. Host selection strategies of parasitoids of phytophagous insects may be largely influenced by chemical signals from plants attacked by insect pests. Their competitive fitness and reproductive success will therefore depend extensively on the ability to employ such signals more efficiently, nature of their life cycle and their adaptive behaviour.

Beckage, N. E. and Templeton, T. J. (1985). Temporal synchronization of emergence of Hyposoter exiguae and $\mathrm{H}$. fugitivus (Hymenoptera: Ichneumonidae) with apolysis preceding larval molting in Manduca sexta (Lepidoptera: Sphinghidae). Annual. Entomological Society Amterderm, 78: 775-782.

Belshaw, R. (1994). Life history characteristics of Tachinidae (Diptera) and their effect on polyphagy. New York: Oxford Univ. Press. pp. 145-62

Benrey, B., Callejas, A, Rios, L., Oyama, K. and Denno, R. F. (1998). The effects of domestication of Brassica and Phaseolus on the interaction between phytophagous insects and parasitoids. Biological Control, 11:130-140. doi:10.1006/bcon.1997.0590

Blanché, S., Casas, J., Bigler, F., and JanssenVan Bergeijk, K. E. (1996). An individualbased model of Trichogramma foraging behavior: Parameter estimation for single females. Journal of Applied Ecology, 33: 425-434. 
BAJOPAS Volume 11 Number 2, December, 2018

Bogran, C. E., Heinz, K. M. and Ciomperlik, M. A. (2002). Interspecific Competition among Insect Parasitoids: Field experiments with whiteflies as hosts in cotton. Ecology, 83: 653-668. doi: $10.2307 / 3071871$.

Boivin, G., and Brodeur, J. (2006). Intra - and Inter - specific interaction among parasitoids: mechanisms, outcomes and biological control. In: Brodeur J.,Boivin $\mathrm{G}$ (eds). Trophic and guild interaction in biological control. Springer, 123 $144 p p$.

Boucek, Z., and Narendran, T. C. (1981). Indian calcid wasps (Hymenoptera) of the genus Dirhinus parasitic on synanthropic and other Diptera. Systematic Entomology, 6(3): $229-51$.

Campbell, B. C., and S. S. Dufey. (1979). Effect of density and instar of Heliothis zea on parasitization by Hyposoter ex iguae. Environmental Entomology,8: 127130.

Corbet, S. A. (1968). The influence of Ephestia kuehniella on the development of its parasite Nemeritis canescens. Journal of Experimental Biology, 48(2):291-304.

Darling, D. C. (2009). "A new species of Smicromorpha (Hymenoptera, Chalcididae) from Vietnam, with notes on the host association of the genus," ZooKeys, 20:155-163.

De Moraes C. M., Cortesero, A M., Stapel, J. O. and Lewis, W. J. (1999). Intrinsic and extrinsic competitive interactions between two larval parasitoids of Heliothis virescens. Ecology \& Entomology, 24:402-10.

De Moraes C. M. and Mescher, M. C. (2005). Intrinsic competition between larval parasitoids with different degrees of host specificity. Ecology \& Entomology, 30:564-70.

Eggleton, P. and Belshaw, R. (1992). Insect parasitoids: an evolutionary overview. Philosophical transaction of the royal society of London. B. 337: 1 - 20.

Eggleton, P. and Belshaw, R. (1993).Comparisons of dipteran, hymenopteran and coleopteran parasitoids: provisional phylogenetic explanations. Biological Journal of Linnean Society,48: 213-226.

Elzinga, R. J. (1977). Observations on Sandalus niger Knoch (Coleoptera: Sandalidae) with description of the triungulin larva.
Journal of the Kansas Entomological Society, 50: 324-328.

Erb, Y. J. (2010). A tri - trophic signal that attracts parasitoids to host damaged plants with stand disruption by non host herbivores. BMC plant biology, 10:247.

Evenhuis, N. L. and O'Hara, J. E. (2008). The status of mesnil's 1949 Diefliegen genus group names (Diptera: Tachinidae) Zoo taxa, $65-68$.

Feener, D. H. and Brown, B.V. (1997). Diptera as parasitoid. Annual Review of Entomology, 42: $73-97$.

Fournet, S., Poinsot, D., Brunel, E., Nénon, J.P. and Cortesero, A.M. (2001). Do female coleopteran parasitoids enhance their reproductive success by selecting highquality oviposition sites? Journal of Animal Ecology, 70 (6), 1046-1052.

Garófalo, C.A., Rozen, J.G. (2001) Parasitic behavior of Exaerete smaragdina with descriptions of its mature oocyte and larval instars (Hymenoptera: Apidae: Euglossini). Am. Mus. Novit. 3349,1-26.

Gaston, K. J. and Hudson, E. (1994). Regional pattern of diversity and estimates of global insect species richness. Biodiversity conservation, 3: 493 - 500.

Gaston, K. J. (2000). Global patterns in biodiversity. Nature 405: $220-227$.

Gauld, I. D. and Bolton, K. (1988).The Hymenoptera. Oxford University press in Association with British museum, National history.

Godfray, H.C.J. (1994). Parasitoids: behavioural and evolutionary ecology. Princeton university press, Princeton, NJ, $473 \mathrm{p}$.

Godfray, H.C.J. (1997). Parasitoid; Behavioral Evolutionary ecology. Annual review of entomology, 42:73-97.

Goergen, G. (2009). Unraveling the diversity of African insects. IITA Benin.

Gols, R., Bukovinszky, T., Van Dam, N. M., Dicke, M., Bullock, J. M. and Harvey, J. A. (2008). Performance of generalist and specialist herbivores and their endoparasitoids differs on cultivated and wild Brassica populations. Journal of Chemical Ecology, 34:132-143.

Goubault, M., Outreman, Y., Poinsot, D., and Cortesero, A. M. (2005). Patch exploitation strategies of parasitic wasps under intraspecific competition. Behav. Ecol. 16:693-701.

Gullan, P.J., and Cranston, P.S. (2004). The insects; an outline by entomology. Blackwell publication, 12: 324-351. 
BAJOPAS Volume 11 Number 2, December, 2018

Gupta, V.K. (1991). The parasitic Hymeroptera and biological control of the African Ichneumonidae. International Journal of Tropical Insects Science, 12(1-2-3):918.

Hailemichael, Y., Schulthess, F., Smith Jr., J., Overholt, W., Chabi-Olaye, A. (2008). Resource allocation and bionomics of indigenous and exotic Cotesia (Hymenoptera: Braconidae) species reared on Sesamia calamistis. Bulletin Entomological Research, 98, 405-415.

Harvey, J. A., Harvey, I. F. and Thompson, D. J. (1994). Flexible larval growth allows use of a range of host sizes by a parasitoid wasp. Ecology, 75(5): 1420 $-1428$.

Harvey, J. A. and Thompson, D. J. (1995). Developmental interactions between the solitary endoparasitoid Venturia canescens (Hymenoptera: Ichneumonidae), and two of its hosts, Plodia interpunctella and Corcyra cephalonica (Lepidoptera: Pyralidae). European Journal of Entomology, 92: 427- 435

Harvey, J. A. (2000). Dynamic effects of parasitism by an endoparasitoid wasp on the development of two host species: implications for host quality and parasitoid fitness. Ecol. Entomol. 25: 267-278.

Harvey, J. A., Kadash, K. and Strand, M. R. (2000). Differences in larval feeding behavior correlate with altered developmental strategies in two parasitic wasps: implications for the size-fitness hypothesis. Oikos, 88(3): 621-629.

Harvey, J. A. and Strand, M. R. (2002). The developmental strategies of endoparasitoid wasps vary with host feeding ecology. Ecology, 83:24392451.

Harvey, J. A., van Dam, N. M. and Gols, R. (2003). Interactions over four trophic levels: food plant quality affects development of a hyperparasitoid as mediated through a herbivore and its primary parasitoid. Journal of Animal Ecology,

72:520 531.doi:10.1046/j.13652656.2003.00722.x

Harvey, J.A., Wagenaar, R. and Bezemer, T. M. (2009). Life-history traits in closely related secondary parasitoids sharing the same primary parasitoid host: evolutionary opportunities and constraints. Entomol. Exp. Appl. 132: 155-164. doi:10.1111/j.15707458.2009.00882.x

Harvey, J. A., Pashalidou, F., Soler, R., Bezemer, T. M. (2011). Intrinsic competition between two secondary hyperparasitoids results in temporal trophic switch. Oikos 120:226-33.

Harvey, J. A., Poelman, E. H., and Tanaka, T. (2013a). Intrinsic inter- and intraspecific competition in parasitoid wasps. Annual Review Entomology, 58:333-351.

Harvey, J. A., Tanaka,T., Magdaraog, P. M. (2013b). Inter- and intra-specific host discrimination in gregarious and solitary endoparasitoid wasps $C$. kariyai and $M$. pulchricornis. Bio-Control, 58:745-754.

Hawkins, B. A. and Lawton, J. H. (1987). Species richness for parasitoids of British phytophagus insects. Nature, 326:788 - 790.

Hawkins, B. A., Shaw, M.R., and Askew, R. R. (1992). Relations among assemblage size, host specialization, climatic variability in North - American parasitoid communities. American Naturalist, 139:58-79.

Hawkins, B. A. (1994). Pattern and process in Host - parasitoid interactions. Cambridge university press, Cambridge. 488p.

Hawkins, B.A., and Sheehan, W. (1994). Parasitoid communities. Ecology. Oxford, united kingdom: oxford university press. $516 \mathrm{p}$.

Heil, M. (2008). Indirect defense via tritrophic interactions. New phytology.178:41-61.

Hemerik, L. and Harvey, J. A. (1999). Flexible larval development and the timing of destructive feeding by a solitary parasitoid: an optimal foraging problem in evolutionary perspective. Ecol. Entomol. 24: $308-315$.

Hespenheide, H. A. (1979). Are there fewer parasitoids in the topics? American Naturalist. 113:766-769.

Hoedjes, K. M., Kruidhof, H. M., Huigens, M. E., Dicke, M., Vet, L.E.M. and Smid, H. M. (2011). Natural variation in learning rate and memory dynamics in parasitoid wasps: opportunities for converging ecology and neuroscience. Proceedings of the Royal Society B: Biological Sciences, 278, 889-897.

Ichiki, R, and Shima H. (2003). Immature life of Compsilura concinnata (Meigen) (Diptera: Tachinidae). Ann. Entomol. Soc. Am. 96:161-67 
BAJOPAS Volume 11 Number 2, December, 2018

Jervis, M. A. and Copland, M. J. W. (1996). The life cycle. In M. A. Jervis and N. Kidd [eds.], Insect natural enemies: practical approaches to their study and evaluation. Chapman \& Hall, London, United Kingdom, 2: 63-161.

Jonasson, T. (1994). Parasitoids of Delia root flies in brassica vegetable crops: coexistence and niche separation in two Aleochara species (Coleoptera: Staphylinidae). Norwegian Journal of Agricultural Sciences (SUPP16), 379386.

Karimzadeh, J. and Wright, D. J. (2008). Bottom-up cascading effects in a tritrophic system: interactions between plant quality and host-parasitoid immune responses. Ecol. Entomol, 33:45-52.

Lasalle, J. and Gauld, I. D. (1991). Parasitic hymenoptera and the biodiversity crisis. Redia. 74: 315 - 334.

Lasalle, J., and Gauld, I.D. (1993). Hymenoptera and biodiversity. CAB international, Oxford.

Letourneau, D. K., Jedlicka, J.A., Bothwell. S.G., and Moreno, C. R. (2009). Effects of natural enemy biodiversity on the suppression of arthropod herbivores in terrestrial ecosystems. Annual Review of Ecology, Evolution and Systematic, 40: $573-592$.

Lewis, W. J., Stapel, J. O., Cortesero, A. M. and Takusi, K. (1998). Understanding how parasitoids balance food and host needs: Importance to biological control. Biol. Control, 11: 175-183.

Lewis, O. T., Memmott, J., Lasalle, J., Lyal, C. H. C., Whitefoord, C. and Godfray, H. C. J. (2002). Structure of a diverse tropical forest insect - parasitoid community. Journal of Annual Ecology, 71: 855 873.

Lou, Y.G., Zhang, G.R., Zhang, W.Q., Hu, Y., Zhang, J. ( 2014). Reprint of: biological control of rice insect pests in China. Biol. Control, 68, 103-116.

Mackauer, R. M. (1990). Host discrimination and larval competition in solitary endoparasitoids. In: M. MackauerLE Ehler]. Roland. Critical Issues in Biological Control. Andover, UK: Intercept. 14-62 pp.

Marino, P. C. and Landis, D. A. (1996). Effect of landscape structure on parasitoid diversity and parasitism in agroecosystems. Ecological Applications, 6: $276-284$.
Matsumura, M. (1992). Life tables of the migrant skipper, Parnara guttata guttata Bremer et Grey (Lepidoptera: Hesperiidae) in the northern peripheral area of its distribution," Applied Entomology and Zoology, 27 (3): 331340.

Mayhew, P. J. and Blackburn, T. M. (1999). Does development mode organize lifehistory traits in the parasitoid Hymenoptera? Journal of Animal Ecology, 68: 906-916.

Meyling, N.V., Navntoft, S., Philipsen, H., Thorup-Jensen, K. and Eilenberg, J. (2013). Natural regulation of Delia radicum in organic cabbage production. Agriculture Ecosystems \& Environment, 164, 183-189.

Miller, S. E., and Rogo, L. M. (2001). Challenges and Opportunities in understanding and utilization of African insect diversity. Cimbebasia, 17: 197 - 218.

Mills, N. J. (1992). Parasitoid guilds, life - style, and host ranges in the parasitoid complexes of torricoid host (Lepidoptera: Tortricoidea). Environmental entomology, 21: 230 239.

Mills, N. J., and Kuhlmann, U. (2004). Oviposition behavior of Trichogramma platneri Nagarkatti and Trichogramma pretiosum Riley (Hymenoptera: Trichogrammatidae) in patches of single and clustered host eggs. Biol. Control, 30: 42-51.

Momoi, S. and Nisida, E. (1994).The effect of crowding in Gregopimpla kuwanae (Hymenoptera: Ichneumonidae): a comparison with its sympatric sibling species," Journal of Insects, 36, 29-35.

Muller, C. B., Adriaanse, I.C.T., Belshaw, R. and Godfray, H. C. J. (1999). The structure of an aphid - parasitoid community. Journal of Animal Ecology, 68: 346 370.

Mumm, R., and Dicke, M. (2010). Variation in natural plant products and the attraction of body guards involved in indirect plant depence. Canadian Journal of Zoology, 88: 628 667.

Naumann, I. D. (1986). "A revision of the IndoAustralian Smicromorphinae (Hymenoptera: Chalcididae)," Memoirs of the Queensland Museum, 22:169187.

Narendran, T. C. (1979)."A new species and a new record of the interesting genus 
BAJOPAS Volume 11 Number 2, December, 2018 Smicromorpha Girault (Hymenoptera: Chalcididae) from Oriental region," Journal of Bombay Natural History Society, 75: 908-911.

Noyes, J.S. (2011). Universal Chalcidoids Database. The natural history Museum. Available on http://www.nhm.ac.uk/researchcuration/projects/chalcidoids/(accessed May 2014)

Noyes, J.S. (1989). The diversity of Hymenoptera in the tropics with specialreference to parasitica in sulawesi. Ecological Entomology, 14: $197-207$.

Price, P.W. (2002). Parasitoids utilizing the same host: adaptive nature of differences in size and form. Ecology, 53: 190-195. doi: 10.2307/1935729 .

Qi, Y.X., Teng, Z.W., Gao, L.F., Wu, S.F., Huang, J., Ye, G.Y. and Fang, Q. (2014). Transcriptome analysis of an endoparasitoid wasp Cotesia chilonis (Hymenoptera: Braconidae) reveals genes involved in successful parasitism. Arch. Insect Biochem. Physiol. 88, 203221.

Quicke, D. L. J., and Van Achterberg, C. (1990). phylogeny of the subfamilies of the family Braconidae (Hymenoptera: Ichneumonidae). National Natuurhistorisch Museum.

Quicke, D. L. J., and Kruft, R. A. (1995). Latitudinal gradients in North American braconid wasp species richness and biology. Journal of Hymenoptera Research, 4:194 - 203.

Quicke, D. L. J. (1997). Parasitic wasps. Chapman and Hall, London. P. 470

Reitz, S. R. (1996). Development of Eucelatoria bryani and Eucelatoria rubentis (Diptera: Tachinidae) in different instars of Helicoverpa zea (Lepidoptera: Noctuidae). Ann. Entomol. Soc. Am. 89(1):81-87.

Rivero, A. and West, A.(2005).The costs and benefits of host feeding in parasitoids. Animal Behaviour, 69: 1293-1301.

Saljogi, A.U.R., Salim, M., Khalil, S. K., and Khurshid, I. (2015). Field application of Trichogramma chilonis (Ishii) for the management of sugarcane borers. Pakistan Journal of Zoology, 47 (3): 783 $-791$.

Saul-Gershenz L. S., Millar J. G. (2006). Phoretic nest parasites use sexual deception to obtain transport to their host's nest. Proceedings of the National Academy of
Sciences of the USA 103 (38): 1403914044.

Shaw, M. R. (1994). Parasitoid host range. In: Hawkins BA, Sheenan W(eds) Parasitoid Community Ecology, pp 111-144. Oxford University Press, New York.

Shaw, M. R. (1997). Rearing Parasitic Hymenoptera. The Amateur Entomologists Society, Kent.

Shaw, M. R., and Huddleston, T. (2012). Classification and Biology of braconid wasps. Handbooks for the Identification of British Insects. 7:11.

Sheehan, W. and Hawkins, B. A. (1991). Attack strategy as an indicator of host range in metopiine and plimpline Ichneumonidae (Hymenoptera). Ecological Entomology, 16: 129-131.

Skillen, E. L., Pickering, J., and Sharkey, M. J. (2000). Species richness of the Campopleginae and Ichneumoninae (Hymenoptera: Ichneumonidae) along a latitudinal gradient in Eastern- Northern American old - growth forests. Environmental Entomology, 29: 460466.

Smilowitz, Z., and Iwantch, G. F. (1973). Relationships between the parasitoid Hyposoter exugiae and the cabbage looper Trichoplusia ni: effects of host age on developmental rate of the parasitoid. Environmental Entomology, 2: 759-763.

Soler, R., Harvey, J. A., and Bezemer, T. M. (2007). Foraging efficiency of a parasitoid of a leaf herbivore is influenced by root herbivory on neighbouring plants functional Ecology, 21(5): 969-974.

Strand, M. R., Johnson, J. A. and Culin, J. D. (1988). Developmental interactions between the parasitoid Wicroplitis demolitor (Hymenoptera: Braconidae) and its host Heliothis virescens (Lepidoptera: Noctuidae). Annual Entomological Society of Amterderm, 81: 822-831.

Sznajder, B. and Harvey, J. A. (2003). Second and third trophic level effects of differences in plant species reflect dietary specialisation of herbivores and their endoparasitoids. Entomologia Experimenta Applicata, 109:73-82. doi:10.1046/j.1570-7458. 2003.00096.x 
BAJOPAS Volume 11 Number 2, December, 2018

Takatoshi, U. (2016) Oviposition and Development in Gregopimpla kuwanae Viereck(Hymenoptera: Ichneumonidae), a Gregarious Ectoparasitoid Wasp. Journal of Insects, Hindawi Publishing Corporation.

1-9pp http://dx.doi.org/10.1155/2016/470637 6

Turlings, T. C., Tumlinson, J., Health, J. H., Proveaux, R. R. and Doolitte, R. E. (1991). Isolation and identification of allelochemicals that attract the larval parasitoid, Cotesia marginiventris (Crresson), to the microhabitat of one of its hosts. Journal of Chemical Ecology, 17: 2235-2251.

Unsicker, S. B., Kunert, G., and Gershenzon, J. (2009). Protective perfumes: The role of vegetative volatiles in plant depense against herbivores. Current opinion plant biology. 12: 479 - 485.
Vereecken, N. J. and Mahe, G. (2007) Larval aggregations of the blister beetle Stenoria analis (Schaum) (Coleoptera: Meloidae) sexually deceive patrolling males of their host, the solitary bee Colletes hederae Schmidt. AnnalesSociete Entomologique de France, 43 (4) : 493-496.

Wajnberg, E. (2006). Time allocation strategies in insect parasitoids: from ultimate predictions to proximate behavioural mechanisms. Behav Ecol Socio. Biol. 60:589-611.

Wharton, R.A. (1993). Bionomics of the braconidae. Annual Review of Entomology,38: $121-43$.

Yu, D.S., Dokko, E. G., Barron, J. R., Schaalje, G. B., Gowen, B. E. (1992). Identification of Ichneumonid wasps using image analysis of wings. Systematic Entomology, 17 (4): 389 395. 